\title{
The Forming Mechanism and Actions on Returns Reverse Logistics in E-Commerce Transactions in China
}

\author{
Ruiqing Zhang, Yinghu Dong \\ School of Economics and Management \\ Nanchang Hangkong University \\ Nanchang City, P.R.China, 330063 \\ E-mail: niatzhrq@163.com
}

\author{
Bhaba R. Sarker* \\ Department of Mechanical and Industrial Engineering \\ Louisiana State University \\ Baton Rouge, LA 70803 \\ E-mail: bsarker@1su.edu
}

\begin{abstract}
This paper explored an exploratory study through case analysis method and comparative analysis methods. The main research objects included large-scale representative ecommerce enterprises and special festival promotion events in China. This paper studied the effect of service quality, policies and network of e-commerce reverse logistics through literature research and statistical analysis method. Besides, this paper also developed the formation mechanism of returns reverse logistics in e-commerce and put forward some actions to reduce returns reverse logistics.
\end{abstract}

Keywords-Reverse logistics; E-commerce; Returns; Cost control; Formation mechanism

\section{INTRODUCTION}

In recent years, the development of e-commerce transactions in China improved remarkably and exhibited its remarkable superiorities in many aspects. Both the number of customers and the amount of consumption increased rapidly each year. According to the statistical report of the 37th China internet development issued by China Internet Network Information Center [1], by the end of December 2015, the number of e-commerce users reached 413 million with a growth rate of $14.35 \%$ and increased 51.83 million users compared with 2014. The monitoring data issued e-commerce reached $\$ 2804.75$ billion in 2015 [2]. By contrast, that of France's was $\$ 70.94$ billion [3], Russia's was $\$ 8.84$ billion [4] and America's was $\$ 341.7$ billion in 2015 [5]. Undoubtedly, these reference data showed that China has already become the greatest country among global e-commerce countries. The rapid development of e-commerce has brought a lot of positive roles for both consumers and producers. It is becoming the new impetus to economic growth. The rapid development of ecommerce inevitably has a huge demand for logistics. Therefore, the logistics industry especially express-delivery industry develops rapidly. The express business volume in 2013 was $¥ 9.19$ billion (US\$:1.46b) with a year-on-year (YOY) growth of $61.6 \%, 14$ billion (US\$: $2.28 \mathrm{~b}$ ) with a YOY growth of $52 \%$ in 2014 and $¥ 20.67$ billion (US\$:3.63b) with a YOY growth of $48 \%$ in 2015. At present, the express business volume of China has also been ranked first in the world. However, along with the increase of e-commerce transactions, the quantity of returns reverse logistics (RRL) also increased.

*Corresponding author: Dr. Bhaba R. Sarker.

The Project of Provincial Educational Reform of Jiangxi, China (No. JXJG-

15-8-14) and The Project of Curriculum Cultivation of Innovation and

entrepreneurship of Nanchang Hangkong University (No. JY-36).
Thus, as an important component of reverse logistics, the RRL also leads to the great demand of logistics warehousing and distribution. Consequently, the profits of e-commerce enterprises and logistics enterprises will decline due to the increase of the costs of warehousing, distribution and labor.

As it appears from the existing literature and market information, the researchers focused mainly on the service quality, policies and network of e-commerce reverse logistics. However, there are very limited literatures and other sources on formation mechanism of RRL of e-commerce. Therefore, the RRL, as such a unique and important aspect in e-commerce in China, should also be systematically researched.

\section{THE FORMATION MECHANISM OF RRL}

\section{A. The products of E-commerce are patchy in terms of quality}

The markets of e-commerce are quite a mixed bag. At the same time, the customers can only see the picture, text or video information of the products through the virtual network transactions in e-commerce, and most of sellers just try to introduce the advantage and positive information relate to the products but weaken or even neglect their shortages. These make the customers can hardly learn thoroughly about the properties and quality of the products they plan to buy. Furthermore, during operation, the e-commerce enterprises can also hardly find the quality problems with omissions and defects which exist before leaving factory. Therefore, the customers will change or refund these products with omissions and defects which they buy from the e-commerce platform undoubtedly. Thus the return reverse logistics appears inevitable.

\section{B. The problems exist in logistics distribution endlessly}

The virtual attribute of e-commerce decides that after the online transaction, it must rely on the offline activities as logistics distribution, transportation and other logistics processes to complete the entire transaction. Therefore, with the rapid development of e-commerce, the self-built logistics by e-commerce enterprise and the third party logistics market emerge gradually. Express delivery business is the main ecommerce logistics currently. Therefore, e-commerce and express industry develop hand in hand and support each other in modern business. However, the problems of the loss, 
damage, trample, and rough sorting and delay delivery to products seriously affect the development of e-commerce enterprises. These problems existed in express delivery industries give rise to a certain damage of property or waste of time both to the customers and e-commerce enterprises. The customers will ask for refund or compensate for their losses, which undoubtedly exacerbated the burden of the returns reverse logistics. The main complaint problems of deliver, delay and loss or shortage are chosen to research in this section (shown in Fig. 1). Comparing all the complaint problems, delivery complaints have become the most important issue among various types of express service complaints. It is becoming not only the bottleneck of the delivery business development but also a key factor which generates returns reverse logistics.
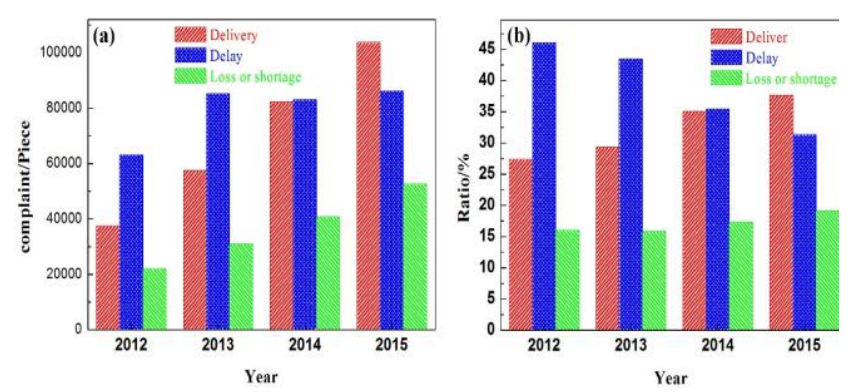

Fig. 1. The main valid complaint items in express delivery business from 2012 to 2015: (a) Complaint items; (b) The ratio of the individual to total complaints

\section{The busy season causes corresponding RRL peak periods}

There are slack as well as busy season for e-commerce business. In order to create a sales peak and stimulate the annual economic income, e-commerce companies are always trying to carry out some promotional activities to improve the shopping enthusiasm of consumers. These varieties of promotions apparently produce huge consumption, but many customers start to complain about e-commerce products every time after a grand shopping. So the returns reverse logistics peak appear just a little late after the sales peak. Though the ecommerce enterprises always keep refund rates as secret, it can also be found the prominent and highlight returns reverse logistics from the relevant statistical data. Based on the statistical data of valid complaints and number of business transactions from SPBC, the peak period and the forming mechanism of returns reverse logistics are discussed and analyzed as following. In order to analyze the annual sales peak period, learn more clearly about the complaints of each month and research the peak period, the comparison chart was built (shown in Figure 3) according to the data from SPBC 2016. Figure 2 indicates that in 2015, the delivery, delay and loss or shortage still is the dominating problems among the valid complaints.

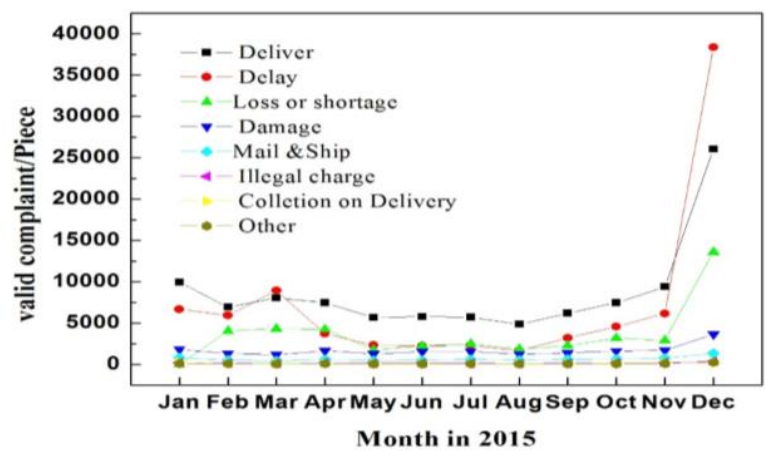

Fig. 2. The comparison chart of valid complaint of each month

\section{The returns come from customers' impulse buying}

Impulse buying is a behavior lacking rational consideration. It is mainly generated by women due to their inherent love of beautiful things, material pursuing and conformity consumption psychology. In addition, women's buying inclination is also affected strongly by intuition, which results in impulse buying because of emotional factors. When these customers received the products, if the color does not match with the website pictures or shape and size do not meet requirement or the new discount promotions appear, they will choose rational return other than impulsive shopping. Thus, the unnecessary returns reverse logistics generate.

\section{E. Other reasons caused by e-commerce enterprises or customers}

Besides the reasons mentioned above, there are also some other reasons caused by e-commerce enterprises or customers.

(a) Wrong products distribution by e-commerce companies.

The wrong products distribution mainly includes customer's name errors and products errors. The errors of the e-commerce order system platform, input error of operators, the ex-warehouse errors of warehouse keepers, express delivery errors and so on will cause the customers receive the wrong goods. These wrong goods will undoubtedly be returned by customers and thus generate the returns reverse logistics.

(b)Wrong order operation causes return.

Some customers may make mistakes such as wrong type-in or wrong choices which they cannot realize in time when filling the orders in e-commerce platform. These customers cannot find the mistake until they receive the goods with wrong number, wrong type, wrong color or other mismatched properties. Therefore, they also choose to return the goods and result in the reverse logistics.

(c) Return the products with on reason.

In many cases, the customers select to return the goods without any quality problem or other deficiency just because they don't like the products any more or they think the goods cannot meet their expectation. 


\section{ACTIONS ON RRL IN E-COMMERCE}

Return is a non-value-added business to the e-commerce businesses. It has a negative effect on inventory costs, operating costs and selling costs from a financial point of view. However, return is essential to create a positive seller-customer relationship, and it can also play a significant role on stimulating the purchase, attracting repeat customers, creating brand loyalty. There are many effect factors on returns reverse logistics. It involves many factors, such as electronic commerce enterprises, logistics distribution enterprises, ecommerce platform, customers and so on. They can take the following measures to reduce the returns reverse logistics.

\section{A. Strengthen the management of e-commerce enterprises}

(a) Choose the suppliers strictly to ensure the product quality. On one hand, e-commerce enterprises must replenish their stock from formal and legal channels and based on the seller's reputation, service attitude and quality of goods. On the other hand, e-commerce enterprises should strengthen communication with suppliers, and collect and feedback the experiences and suggestions of customers to the suppliers or factories. This will assist the suppliers or factories to improve manufacturing process as well as the products' quality. By this way, the returns reverse logistics can be constrained from the source.

(b) Provide the real information and eliminate the false propaganda. In the case of the shape and the quality of the commodity being established, in order to lower the rate of return, e-commerce enterprises should try to provide the complete and detailed text description, multi-directional and multi-angle high quality images display, and detailed video commentary. These will facilitate the customer reduce the asymmetric or incomplete information and to make a correct purchasing decision with a comprehensive understanding of the products.

(c) Response to customer needs timely and improve service quality. E-commerce enterprises should provide good pre-sale, mid-sale and after-sale service, timely respond to all kinds of questions and answer to the customers, solve the customer's doubts, enhance customers' satisfaction and obtain the customers' trust and loyalty. By these ways, the ecommerce enterprises could provide the fast and convenient returns logistics as well as reduce the negative evaluation.

(d) Adjust marketing strategy and reduce the refund rate of sales peak period. On the one hand, e-commerce enterprises should adjust pricing strategy to maintain the healthy development of e-commerce. They should regularly provide inexpensive goods with high quality, so that consumers would not be concentrated in one-day buying. On the other hand, e-commerce enterprises should pre-process the promotion of the sales peak. They should notice customers the detail promotion information about the price, quality and so on before the festival promotion day eve. They can ensure the amount of sales by means of receiving the advance deposit payment and then accepting the residual balance on the festival day or when the customers received the products. By this way, the warehouse manager of e-commerce enterprises can prepare and distribute the order ahead of the sales peak and inform the express companies the logistics needs and to arrange the logistics and distribution in advance. Eventually, this strategy would not only alleviate the pressure of sales and warehouse stock, improve the service quality of order, warehouse management, distribution and delivery, but also reduce return rate caused by the problems as warehouse blocking, delay and so on.

\section{B. Strengthen the operation management and improve service quality of logistics}

Pan and Zinkhan [6] proposed that service quality has most important roles to customers' choices. Padmanabhen [7] pointed out that according to the reasonable returns policy, the distributors cannot only strengthen the competition ability but can also obtain great benefits. Andrade et al. [8] proposed that well-structured processes would meet customer needs better, improve customers' loyalty and provide opportunity for companies to gain competitiveness. The situation of Chinese ecommerce market is more enormous and complicated than any other countries'. Therefore, deeper and more systemically studies should be carried on to improve the service quality and avoid returns reverse logistics.

(a) To strengthen staff management and reduce return rate of service quality. Firstly, logistics enterprises should hire specialists to guide and train the staff on spot. Secondly, the new staff must receive pre-job training program. Thirdly, assess the return logistics system regularly. Finally, allocate staff resource rationally.

(b) Improve efficiency of forward logistics delivery and reduce damage/delay return rate. E-commerce enterprise should scientifically package the goods according to the features of products, the distribution number, transportation ways, distance and location. Thus it can prevent the damage to goods, shorten the delivery cycle and return rate. In addition, it is necessary to reduce the loss, wrong delivery, untimely delivery and other issues caused by the negligence of the staff. If the distribution problems appear, the relative staff should timely communicate with consumers and put forward returning or exchanging the goods, or fee waiver and free gifts to reduce the losses of consumers and improve the reputation of enterprise.

(c) Reduce the cost of reverse logistics and improve the efficiency of logistics distribution. Transport costs are the main cost of reverse logistics and account for about $40-50 \%$ to total. Therefore, to reduce the logistics cost of returns reverse logistics, the enterprises should seize this core link. Ecommerce enterprise and related logistics enterprises should pay attention to the efficiency management, reasonable scheduling and truck distribution program management. They must improve the loading rate, utilization rate and vehicle operation management, scientifically management the vehicle matching plans or purchase plan, reduce unnecessary distribution, improve the transportation speed, reduce transportation cost, improve the efficiency of logistics and distribution and timely complete the returns reverse logistics business. 
(d) Construct efficient reverse logistics information system. First of all, the logistics enterprises should improve the reverse logistics information system to effectively control the cost of reverse logistics, standardize the operation of all aspects of logistics and reduce unnecessary costs. Next, establish an efficient reverse logistics information system which can integrate the e-commerce service department, the warehouse department and the third party logistics information. It can also provide consumers with accurate return information and status in time. The last, the logistics enterprises should learn thoroughly about the return reason of customers, the coordination status of each returns logistics link by analyzing the return information data from reverse logistics information system. In addition, they can also adjust some service to achieve continuous improvement in returns reverse logistics according to the information system.

\section{Cooperate with up-and-down stream enterprises, integrate and optimize supply chain}

Suppliers, e-commerce companies and express (logistics) companies constitute a supply chain system. The information communication, division and cooperation among these companies are very important to cost saving and efficiency in returns reverse logistics. The core function of the supply chain is already realized through collaboration. All companies can achieve win-win benefits. E-commerce enterprises can strengthen the information circulation between the upstream suppliers and downstream logistics companies and express companies to optimize the value chain, achieve vertical integration and ensure the returns reverse logistics run with the lowest cost.

\section{Improve e-commerce returns logistics policies to protect the interests of consumers}

Return policy is the bridge to connect the e-commerce companies and customers. Most of the researchers agree with this point and manage to propose reasonable and scientific return policy based on their enormous researches. However, the China e-commerce market is more complicated and tremendous than others. The more systematical and comprehensive returns policy should be made. On one hand, ecommerce enterprises should make a reasonable returns policy and ensure consumers can fully and clearly understand the returns policy before shopping. On the other hand, the relevant departments should improve the law section or clause of the return policy and strengthen the supervision.

\section{CONCLUSION}

The rapid development of the internet technology has brought great opportunities as well as many challenges to ecommerce enterprises. Among all the challenges, how to solve the existing problems in reverse logistics efficiently is one of the inevitable challenges for e-commerce enterprises. This research developed the formation process and mechanism of returns reverse logistics based on analyzing the professional data of spot check issued by AQSIQ and consumer complaint data issued by SPBC of e-commerce products and combining the characteristics of slack and boom sale seasons.
Poor quality in deliver service, delay and loss/shortage are the core reason for forming returns reverse logistics, especially the quality of delivery service is the most concerned aspect of customers during the course of e-commerce transactions currently. Experimental design and methodological approach based on the existing or potentially prevailing theory were followed to respond to the desired queries. The exercise includes implications for developing returns reverse logistics network for improving the operating efficiency and lowering the cost. The returns policy will include the return conditions, procedures, price, refund rate, shipping cost sharing, refund ways, and other aspects. This will reduce the embarrassment of consumers who buy the goods cannot be returned due to not fully understanding the returns policy. The reasonable returns policy can not only reduce the number of returns, but can also maintain the credibility of the e-commerce enterprises. It will also imply enhanced customer confidence, eliminate the customer's worry, improve customer repeat purchase rate, and improve corporate image, expand the market share of the enterprise and enhance the competitive advantages.

\section{ACKNOWLEDGMENT}

This paper is financially supported by The Project of Provincial Educational Reform of Jiangxi, China (No. JXJG15-8-14) and The Project of Curriculum Cultivation of Innovation and entrepreneurship of Nanchang Hangkong University (No. JY-36). Grateful acknowledgement goes to them!

\section{REFERENCES}

[1] China Internet Network Information Center, "The 37th Statistical Report on Internet Development in China," http://www.cnnic.cn/hlwfzyj/hlwxzbg/hlwtjbg/201601/t20160122_5327 1.htm, January 27, 2016.

[2] China E-commerce Research Center, "2015 Annual Chinese ecommerce market data monitoring report," www.100ec.cn/zt//2015ndbg, May 17, 2016.

[3] Ecommerce News, "Ecommerce in France was worth $€ 65$ billion in 2015," http://ecommercenews.eu/ecommerce-france-worth-e65-billion2015/, January 29, 2016.

[4] Ecommerce News, "Cross-border ecommerce in Russia is booming," http://ecommercenews.eu/cross-border-ecommerce-russia-booming/, February 10, 2016.

[5] Zaroban S., "US e-commerce grows $14.6 \%$ in 2015," https://www.internetretailer.com/2016/02/17/us-e-commerce-grows146-2015, February 17, 2016

[6] Y. Pan , G. M. Zinkhan, , "Determinants of Retail Patronage: A Metaanalytical Perspective, ”Journal of Retailing, 82(3): 229-243, 2006.

[7] V. Padmanabhen, "Return Policies: Make Money by Making Good," Sloan Management Review, 16(1): 65-72, 1995.

[8] R. P. Andrade, W. C. Lucato, R. M. Vanalle, M. V. Junior, "Review of the Relationship between Reverse Logistics and Competitiveness," Adv. Materials Research,(845): 614-617, 2014. 